\title{
Tobacco use and mortality due to cardiovascular disease, malignancy and allcauses in a large cohort
}

\author{
Johnson LR ${ }^{1}$, Siddaiah $\mathbf{R S}^{2}$ \\ ${ }^{1}$ Dr LiaquatRoopesh Johnson, Associate Professor, Department of Community Medicine, ${ }^{2}$ Dr Rangaswamy Siddaiah, \\ Associate Professor, Department of General Medicine. Both are affiliated with DM Wayanad Institute of Medical \\ Sciences, Wayanad, Kerala
}

Address for Correspondence: Dr. LiaquatRoopesh Johnson, E-mail: liaquat99@ gmail.com

\begin{abstract}
Introduction: $67.6 \%$ of all Non-Communicable Disease (NCD) deaths are attributable to Cardiovascular Diseases (CVDs) and Cancers. Of the 14.2 million annual deaths attributable to modifiable behavioural factors, tobacco use accounts for 6 million (42.2\%). This study aims to determine the relationship between tobacco use and mortality due to cardiovascular diseases (CVDs), malignancy, and all-causes among adults ( $>18$ years) in the US. Materials and Methods: A cohort of 96164 adults with data on tobacco use was selected from the public-use dataset of the US National Longitudinal Mortality Study (NLMS). The various forms of tobacco use- smoking, smokeless, both smoking and smokeless- were examined in relationship to specific-cause and all-cause mortality. Results: In bivariate analyses age category and sex were identified as possible confounders. Separate analyses were performed for CVD mortality, cancer mortality and all-cause mortality. Factors that reached statistical significance were subjected to multivariate analyses. Apart from age category, daily cigarette smoking was significantly associated with both cancer and CVD mortality (p: $<0.0001)$. There was a statistically significant relationship between age category, sex, any tobacco use and all-cause mortality ( $\mathrm{p}$ : <0.0001). Conclusions: CVD and cancer mortality in the US are significantly associated with daily cigarette smoking. All-cause mortality in the US is associated with any tobacco use.
\end{abstract}

Key words: Tobacco use, Preventable mortality, Cohort.

\section{Introduction}

Globally, Non-communicable diseases (NCDs) kill more people than any other cause, accounting for 38 million deaths annually [1,2]. $67.6 \%$ of all NonCommunicable Disease (NCD) deaths are attributable to Cardiovascular Diseases (CVDs) and Cancers. Of the 14.2 million annual deaths attributable to modifiable behavioural factors, tobacco use accounts for 6 million $(42.2 \%)[1,2]$.

Globally, tobacco use is responsible for $22 \%$ of all cancer deaths and $10 \%$ of all deaths from cardiovascular diseases (CVDs) [3]. Among the six WHO Regions, the Americas and European regions have the highest proportion of deaths attributable to tobacco [3].Smoking accounts for about $85 \%$ of all tobacco produced globally, and is considerably more

Manuscript received $6^{\text {th }}$ April 2016

Reviewed: $17^{\text {th }}$ April 2016

Author Corrected: $25^{\text {th }}$ April 2016

Accepted for Publication $8^{\text {th }}$ May 2016 hazardous than exposure to second-hand smoke [4]. There is no safe level of exposure to second-hand tobacco smoke [5]. Tobacco use has been described as the leading preventable cause of death in the United States (US) [6]. Compared to people who have never smoked, both male and female smokers in the US experience approximately three times higher mortality.

Cancer, respiratory and vascular diseases are the major causes of excess mortality among smokers in the US [6]. Each year, about $20 \%$ of all deaths in the US are attributable to cigarette smoking. This includes deaths from exposure to first-hand and second-hand smoke. Smoking cessation before 40 years' age reduces the risk of death due to a smoking related disease by around $90 \%[6,7]$.

Smoking is causally associated with several cancerslung, bladder, oesophagus, mouth/pharynx, cervix, 
larynx, kidney, pancreas, liver and colorectal cancer [7]. Not all cancers have similar survival rates, and there are sex differences as well [7].

There is now sufficient evidence that even brief exposure to tobacco smoke- either from smoking or exposure to second-hand smoke- can cause the progression of chronic vascular disease, and acute cardiovascular events [7]. 28\% of Coronary Heart Disease (CHD) deaths in the US among men, and nearly $20 \%$ among women are attributable to smoking [7].

This study aims to examine the relationship between tobacco use and death due to cardiovascular disease, malignancy, and all causes in the US.

\section{Materials and Methods}

For this study, we used the public-use file identified as File tu, of the National Longitudinal Mortality Study (NLMS). The NLMS is a longitudinal study that is used to assess socio-economic, demographic and occupational factors' association with cause-specific and all-cause mortality in the United States of America [8]. The data in the public-use files are de-identified, and are representative of the civilian, noninstitutionalized population of the USA. The public-use NLMS (version 5) file consisted of five separate files, each having individual-level data that represented a specified duration of follow-up and decade of study. The File tu consists of 493,282 individual level entries with data on tobacco use, of which we selected all
96,164 entries of persons above 18 years' age. Ethical Committee approval was not required since all data were publicly available, data are de-identified, and the study did not require human participant interactions.

We restricted our analyses to an examination of the variables associated with tobacco use, and the occurrence of death due to CVDs, malignancy, or all causes. These included current cigarette smoking status, age at which the respondent started smoking, use of any other tobacco product for smoking, ever use of smokeless tobacco, consumed at least 100 cigarettes during one's lifetime, etc. Data were recoded to create variables that were binary. In addition, details from several variables were combined to create a new variable that documented of the person had ever used a tobacco product, regardless of type.

Data analyses were performed separately for the three dependent variables in question- death due to CVD; death due to cancer; and death due to any cause. The grouping of cause of death was performed on the basis of available cause of death codes and current knowledge [7].

Data were analysed using $\mathrm{R}$ version 3.2.4 Revised and the package Rcmdr Plugin EZR[9,10]. Bivariate analyses were performed using the $\chi^{2}$ Test. Statistical significance was fixed at the $5 \%$ level. Categorical variables that reached statistical significance on bivariate analyses were included in logistic regression models for multivariate analyses.

\section{Results}

There were 44971 males, and 51193 females in the study data set.92,304 (95.99\%) of the 96164 subjects were alive. Of the 3858 who had died, the leading causes of death were Acute Myocardial Infarction (530[0.55\%]), other forms of chronic ischaemic heart disease $(423[0.44 \%])$, malignancies of the Trachea, bronchus and lung (292[0.30\%]), and cerebrovascular diseases (250[0.26\%]).987 persons had died due to a malignancy, while 1783 had died due to cardiovascular diseases.

While 48,078 had never smoked cigarettes, an almost equal number, 48086, smoked cigarettes daily. All those who smoked daily had smoked at least 100 cigarettes in their lifetime.

As quitting smoking before age 40 years lowers the risk of smoking related death by around $90 \%, 40$ years was taken as the threshold to create the variable age category [6,7].

The results of bivariate analyses for selected factors are presented in Table 1.From the table, it is seen that age category and sex were significantly associated with CVD mortality and all-cause mortality. While age category was significantly associated with cancer mortality, sex failed to reach statistical significance. 
Table 1: Results of bivariate analyses of selected variables.

\begin{tabular}{|c|c|c|c|c|c|c|c|c|c|c|}
\hline \multirow{2}{*}{ Variable } & \multirow{2}{*}{ Level } & \multicolumn{2}{|c|}{ Status } & \multirow{2}{*}{ p value } & \multicolumn{2}{|c|}{ Death due to } & \multirow{2}{*}{ p value } & \multicolumn{2}{|c|}{ Death due to } & \multirow{2}{*}{$p$ value } \\
\hline & & Dead & Alive & & CVD & Other & & Cancer & Other & \\
\hline \multirow{2}{*}{$\begin{array}{l}\text { Smokeless } \\
\text { tobacco }\end{array}$} & Ever used & 154 & 2714 & \multirow[b]{2}{*}{0.0002} & 79 & 75 & \multirow[b]{2}{*}{0.22} & 31 & 123 & \multirow[b]{2}{*}{0.13} \\
\hline & $\begin{array}{l}\text { Never } \\
\text { used }\end{array}$ & 3686 & 89119 & & 1695 & 1991 & & 951 & 2735 & \\
\hline \multirow{2}{*}{$\begin{array}{l}\text { Any } \\
\text { Tobacco } \\
\text { product }\end{array}$} & Ever used & 2394 & 47748 & \multirow[b]{2}{*}{$<0.0001$} & 1039 & 1355 & \multirow[b]{2}{*}{$<0.0001$} & 662 & 1732 & \multirow[b]{2}{*}{0.0001} \\
\hline & $\begin{array}{l}\text { Never } \\
\text { used }\end{array}$ & 1464 & 44556 & & 744 & 720 & & 325 & 1139 & \\
\hline \multirow{2}{*}{$\begin{array}{l}\text { Cigarette } \\
\text { smoking } \\
\text { status }\end{array}$} & $\begin{array}{l}\text { Daily } \\
\text { smoker }\end{array}$ & 2290 & 45796 & \multirow{2}{*}{$<0.0001$} & 984 & 1306 & \multirow{2}{*}{$<0.0001$} & 640 & 1650 & \multirow{2}{*}{$<0.0001$} \\
\hline & $\begin{array}{l}\text { Never } \\
\text { smoked }\end{array}$ & 1568 & 46508 & & 799 & 769 & & 347 & 1221 & \\
\hline \multirow{2}{*}{$\begin{array}{l}\text { Age } \\
\text { category }\end{array}$} & $>40$ years & 3661 & 43222 & \multirow{2}{*}{$<0.0001$} & 1751 & 1910 & \multirow{2}{*}{$<0.0001$} & 952 & 2709 & \multirow{2}{*}{0.01} \\
\hline & $\leq 40$ years & 197 & 49082 & & 32 & 165 & & 35 & 162 & \\
\hline \multirow{2}{*}{$\begin{array}{l}\text { No. of } \\
\text { cigarettes } \\
\text { smoked in } \\
\text { life }\end{array}$} & $\begin{array}{l}<100 \\
\text { cigarettes }\end{array}$ & 1568 & 46508 & \multirow{2}{*}{$<0.0001$} & 799 & 769 & \multirow{2}{*}{$<0.0001$} & 347 & 1221 & \multirow{2}{*}{$<0.0001$} \\
\hline & $\begin{array}{l}\geq 100 \\
\text { cigarettes }\end{array}$ & 2290 & 45796 & & 984 & 1306 & & 640 & 1650 & \\
\hline \multirow{2}{*}{ Sex } & Female & 1714 & 49478 & \multirow{2}{*}{$<0.0001$} & 836 & 878 & \multirow{2}{*}{0.004} & 433 & 1281 & \multirow{2}{*}{0.71} \\
\hline & Male & 2144 & 42826 & & 947 & 1197 & & 554 & 1590 & \\
\hline
\end{tabular}

Table 2: Results of Logistic Regression Analyses.

\begin{tabular}{|c|c|c|c|c|}
\hline \multicolumn{5}{|c|}{ Dependent variable: Death due to any cause (1. Dead) } \\
\hline \multirow{2}{*}{ Variable } & \multirow{2}{*}{ Odds Ratio } & \multicolumn{2}{|c|}{$95 \%$ Confidence Interval } & \multirow{2}{*}{ p value } \\
\hline & & Lower limit & Upper limit & \\
\hline Age Category (>40 years) & 21.10 & 18.20 & 24.40 & $<0.0001$ \\
\hline Sex (Female) & 0.67 & 0.63 & 0.72 & $<0.0001$ \\
\hline $\begin{array}{l}\text { Any Tobacco use } \\
\text { (Ever used tobacco) }\end{array}$ & 1.15 & 1.07 & 1.24 & $<0.0001$ \\
\hline $\begin{array}{l}\text { Smokeless tobacco use } \\
\text { (Ever used smokeless) }\end{array}$ & 1.14 & 0.96 & 1.36 & 0.12 \\
\hline \multicolumn{5}{|c|}{ Dependent variable: Death due to CVD (1. CVD death) } \\
\hline Age category (>40 years) & 4.71 & 3.21 & 6.93 & $<0.0001$ \\
\hline $\begin{array}{l}\text { Cigarette smoking status } \\
\text { (Daily smoker of cigarettes) }\end{array}$ & 0.72 & 0.63 & 0.82 & $<0.0001$ \\
\hline \multicolumn{5}{|c|}{ Dependent variable: Death due to Malignancy (1. Cancer death) } \\
\hline $\begin{array}{l}\text { Cigarette smoking status } \\
\text { (Daily smoker of cigarettes) }\end{array}$ & 1.37 & 1.18 & 1.59 & $<0.0001$ \\
\hline Age category (>40 years) & 1.65 & 1.13 & 2.39 & 0.008 \\
\hline
\end{tabular}

The use of any tobacco product, smoking at least 100 cigarettes during one's lifetime, and daily cigarette smoking were significantly associated with all-cause mortality, CVD mortality, and cancer mortality. As advancing age by itself increases the risk of CVD and cancer; and sex predilections exist for both CVD and cancer, the possibility that these two factors are confounders was considered. Multiple logistic regression analyses were performed separately for the following dependent variables: death due to CVD; death due to cancer; and death due to any cause. The results of logistic regression analyses are presented in Table 2.From Table 2 it is seen that apart from the possible confounders- age category and sex, daily cigarette smoking is significantly associated with both CVD and cancer mortality. However, any tobacco use is significantly associated with all-cause mortality. 


\section{Discussion}

The results indicate that while daily cigarette smoking is associated with higher odds (1.37) of death due to malignancy (compared to those who have never smoked cigarettes), it is associated with lower odds (0.72) of dying due to CVD. While this may appear to indicate a protective effect against CVD for those who smoke cigarettes daily, careful examination of the results indicate otherwise. Considering the odds of dying from any cause, it is clear that those who use tobacco in any form have a higher risk of mortality (Odds Ratio 1.15) compared to those who have never used tobacco ( $\mathrm{p}$ : $<0.0001)$. Similarly, the odds of death due to malignancy for tobacco users (specifically those who smoke cigarettes daily) is higher (Odds Ratio 1.37) than those who never smoked cigarettes.

Against this background, the lower odds for death due to CVDs are anomalous. We suggest that the relatively low risk of CVD mortality for daily cigarette smokers masks the excess mortality due to other causes- notably malignancy. Thus, while daily cigarette smokers appear to have a lower risk of dying from cardiovascular diseases, actually their risk of dying of any cause is higher. The lower odds of dying from CVDs merely indicate the higher odds of dying from other conditions, possibly before death due to CVDs. There are several causes that are not currently established as attributable to smoking, and may account for as much as $17 \%$ of the excess mortality due to smoking [11].

As we did not have access to data on height and weight, it was not possible to determine if overweight/ obesity was influencing the findings [12]. Other investigators have reported that compared to individuals who never smoked, mortality among current smokers is between 2 to 3 times higher [11]. Unfortunately, due to lack of data pertaining to current smoking status, we were unable to evaluate the same. However, the fact that the use of any tobacco product is associated with higher odds of death,should motivate the adoption of the global target to achieve a $30 \%$ relative reduction in current tobacco use by 2020 proposed by the World Health Organization [13].

Although this study benefits from a large sample that is representative of the civilian US population, there are several limitations. The biggest limitation is the lack of clarity regarding certain aspects of tobacco use in the data. This severely restricts analyses, and limits it to those variables that do not suffer from this problem.
Further, the data has limited external validity due to the fact that the data pertains to the $1980 \mathrm{~s}$, and several interventions and programs in the US have addressed the issue of tobacco use since then. Moreover, most members of the study population were white [11]. The lack of data pertaining to key behaviour patterns that might have influenced mortality patterns between smokers and non-smokers prevented the adjustment of those factors as confounders. In addition, mortality patterns are not uniform through the various stages of malignancies, or similar for different malignancies [7]. The consolidation of deaths due to malignancy would therefore potentially underestimate the risk of death due to tobacco use/ smoking for several cancers. The greatest proportion of deaths due to CVDs were on account of Acute Myocardial Infarction and chronic heart disease. Pooling other cardiovascular causes of death would similarly have reduced the overall odds of death due to CVDs.

\section{Conclusions}

CVD and cancer mortality in the USA are significantly associated with daily cigarette smoking. All-cause mortality in the USA is associated with the use of any tobacco product.

Acknowledgement: This paper uses data obtained from the de-identified public use file of the US National Longitudinal Mortality Study (NLMS). The National Longitudinal Mortality Study is a collaborative effort between the US Census Bureau and the National Heart, Lung, and Blood Institute (NHLBI), National Cancer Institute (NCI), National Institute on Aging (NIA), and the National Center for Health Statistics (NCHS). The views expressed in this paper are those of the authors and do not necessarily reflect the views of the Census Bureau, NHLBI, NCI, NIA or NCHS.

Funding: Nil, Conflict of interest: None initiated. Permission from IRB: Yes

\section{References}

1. World Health Organization. WHO web site. [Online].; 2015 [cited 2016 May 4. Available from: www.who.int/ mediacentre/factsheets/fs355/en/.

2. World Health Organization. WHO web site. [Online]; 2014 [cited 2016 May 4. Available from: http://apps.who.int/iris/bitstream/10665/148114/1/9789 


\section{4_eng.pdf?ua=1.}

3. World Health Organization. WHO web site. [Online].; 2005 [cited 2016 May 5. Available from: http://www.who.int/tobacco/publications/surveillance/fa ct_sheet_mortality_report.pdf.

4. Jha P. Avoidable Deaths from Smoking: A Global Perspective. Public Health Rev 2012; 33(2): 569-600.

5. World Health Organization. WHO web site. [Online].; 2015 [cited 2016 May 6. Available from: http://www.who.int/mediacentre/factsheets/fs339/en/.

6. Centers for Disease Control and Prevention. CDC web site. [Online].; 2015 [cited 2016 May 6. Available from: http://www.cdc.gov/tobacco/data_statistics/fact_ sheets/health_effects/tobacco_related_mortality/.

7. Centers for Disease Control and Prevention (US). Smoking-Attributable Morbidity, Mortality and Economic Costs. In The Health Consequences of Smoking-50 Years of Progress: A Report of the Surgeon General. Atlanta: Centers for Disease Control and Prevention (US); 2014.

8. Singh GK, Siahpush M. Ethnic-Immigrant Differentials In Health Behaviours, Morbidity And Cause-Specific Mortality In The United States: An analysis Of Two National Data Bases. Human Biol. 2002 February; 74(1): 83-109.

9. R Core Team (2016). R: A language and environment for statistical computing. R Foundation for Statistical Computing, Vienna, Austria. 2016. URL: https:// www.R-project.org/.

10. Kanda Y. Investigation of the freely available easyto-use software 'EZR' for medical statistics. Bone Marrow Transplant. 2013 Mar;48(3): 452-8. doi: 10.1038/bmt.2012.244. Epub 2012 Dec 3.

11. Carter BD, Abnet CC, Feskanich D, Freedman ND, Hartge P, Lewis CE, et al. Smoking and MortalityBeyond Established Causes. N Engl J Med. 2015 Feb 12;372(7):631-40. doi: 10.1056/NEJMsa1407211.

12. Wang $Z^{1}$, Liu M, Pan T, Tong S.. Lower Mortality Associated With Overweight in the US National Health Interview Survey: Is Overweight Protective? Medicine (Baltimore). 2016 Jan;95(2):e2424. doi: 10. 1097/MD.0000000000002424.

13. World Health Organization. WHO web site. [Online].; 2013 [cited 2016 May 6. Available from: http://apps. who.int/iris/bitstream/10665/94384/1/97892 41506236_eng.pdf?ua=1.

\section{How to cite this article?}

Johnson LR, Siddaiah RS. Tobacco use and mortality due to cardiovascular disease, malignancy and allcauses in a large cohort. Int J Med Res Rev 2016;4(5):736-740.doi: 10.17511/ijmrr.2016.i05.12. 